\title{
Broken Windows Theory: Time To Reevaluate And Reform A Failing Approach With The Help Of Communities
}

\author{
Prairie Schappert*
}

\begin{abstract}
Broken windows theory is a predominant concept that is used to influence policing and legislation enforcement. In today's society, the use of such force and regulation is being questioned due to its harm and negative effects. Broken windows theory has created the marginalization and criminalization of the poor, the homeless and the destitute. Claiming such communities as broken window areas due to social and physical disorder, leads to stigmatization through invasive police force tactics. Broken windows theory and policing must be reformed and re-evaluated to facilitate community growth, while encouraging responsibility to care for citizens. The introduction of community oriented policing into neighbours is the beginning of aiding police through citizen interaction and building social cohesion.
\end{abstract}

Keywords - broken windows policing, criminalization, social and physical disorder, social control, social cohesion, community oriented policing

"If a window in a building is broken and is left unrepaired, all the rest of the windows will soon be broken" (Dunham \& Alpert, 2015, p. 456). This quotation demonstrates the core beliefs and values of broken windows theory, which influences current policy and policing (Dunham \& Alpert, 2015). Broken windows theory has become an invasive and controversial theory that is now relied upon by numerous legislators and police task forces. Through the implementation of broken windows policing, many communities have become marginalized and targeted by zero-tolerance policing (Jefferson, 2016). These are often communities who need the most help from authorities, but instead are suffering due to the style of policing and law enforcement (Jefferson, 2016).
Upon analysis of broken windows theory, I question the ideology of this theory and potential alternatives that could be used to change unsuccessful, and at times ineffective, policy and policing. Broken windows theory is a negative outdated style of rule and policing that can be re-evaluated through numerous sociological theories, such as, discourse theory and critical race theory, while reforming to fit within the individual and societal needs of modern day communities. Therefore, the process could begin where marginalized neighbourhoods would no longer be oppressed by the criminalization of poverty and homelessness. This can be proven by analyzing and discussing the overall concept of broken windows theory,

*Department of Sociology, College of Arts and Science, University of Saskatchewan, Saskatoon, SK, Canada

Correspondence: pvs885@mail.usask.ca 
the critiques towards the theory, sociological concepts that explain the downfall of broken windows theory, how the system can be reformed, and the idea of community policing.

\section{Broken Windows Theory}

Broken windows theory is a criminological theory based on the norm setting and signaling effect of urban disorder, crime and anti-social behaviour (Boggess \& Maskaly, 2014). This idea focuses on the conclusion that levels of minor disorder and subsequent levels of violent crime are indistinguishably linked (Boggess \& Maskaly, 2014). Disorder is seen as causing crime, or one of the leading factors engaging in the end result of crime. A single instant of disorder can spark a chain reaction of community decline if not dealt with (Gau \& Pratt, 2010). Hence, the general state of an area and neighbourhood affects people's judgement about disorder and crime (Gau \& Pratt, 2010). Broken windows theory has been implemented within policing and policy as a way to get tough on crime. This theory projects the need of police forces to focus on small problems that could then lead to bigger issues. If police help residents enforce basic rules about street behaviour, such problems could be limited (Steenbeek \& Kreis, 2015). Police can more effectively reduce crime through control of visible disorder and nuisance behaviour (Boggess \& Maskaly, 2014). Broken windows theory claims that maintaining and monitoring urban environments to prevent small crimes like intoxication, vandalism and panhandling will create an atmosphere of order and lawfulness, along with preventing more serious crimes (Sampson \& Raudenbush, 2004). Small crimes such as those indicated above are explained by broken windows theory as being social and physical disorders.

Social disorders can be explained in the context of what the majority of individuals understand as being deviant, disruptive, or actions classed as socially unacceptable, such as prostitution and homelessness (Sampson \& Raudenbush, 2004). Physical disorders can be described as cues and signs that can be visibly seen such as graffiti, vandalism, garbage or dirty streets (Sampson \& Raudenbush, 2004). Broken windows theory asserts that the shared perception of danger is visible disorders, both social and physical, in public spaces that beckon deviance and violent crime (Jefferson, 2016). Observable physical disorder in neighbourhoods plays a strong role in shaping how residents determine the level of social disorder believed to be present in the same neighbourhoods. The assumption is that each disorder present within a community feeds and fuels off one another. Individuals believe if physical disorder is visible there must be social disorder and vice versa; therefore, they co-exist and influence neighbourhood disorder (Hinkle \& Yang, 2014). Broken windows theory suggests that even the smallest incident of disorder gone unchecked could initiate a domino effect of crime in a community if not addressed in a timely manner. Consequently, social and physical disorders lead to crime which signals a loss of control (Hinkle \& Yang, 2014). This theory claims that the idea of lack of control can induce fear within neighbourhoods (Gau, Corsaro \& Brunson, 2014), and fear $* *$ is seen as a vital influencing factor that controls many individual's actions and beliefs.

Disorder symbolizes a breakdown of social control, and loss of control inspires fear. Disorder and crime share a relationship that is not direct, but instead, is mediated by fear and loss of social control (Hinkle \& Yang, 2014). Social and physical disorders cause a breakdown in people's beliefs of neighbourhoods and community which then causes fear. There is a connection between observed physical disorders and heightened fear of crime that occurs through dilapidated community conditions, which raises individual's perceptions of social disorder (Hinkle \& Yang, 2014). Fear is central to broken windows theory in connection to the process of disorder and crime. Fear is elevated, as the perception of disorder rises; therefore, disorder is the source of fear (Gau et al., 2014). Broken windows theory explains fear contributes to community destabilization, which allows crime to seep in. Specific actions and disorder are feared by individuals and this fear solidifies the distaste for such behaviours (Dunham \& Alpert, 2015, pp. 455-467). Fear-disorder relationship is mediated by intervening social mechanisms such as authority, legislation, policy and police forces. Social mechanisms are key to disorder-fear relationships because they are implemented to control and limit fear (Gau et al., 2014). These mechanisms influence the social control and cohesion within neighbourhoods.

The effect of disorder on fear is funneled through social control and cohesion (Gau et al., 2014). Social control is implied through the use of police enforcing policy and public order. Broken windows theory claims that crime is directly linked to social order (Engel et al., 2014). Social control is weakened when fear is associated with disorder because people avoid fear and the individual or object that causes such fear. In high disorder neighbourhoods, social control and cohesion cannot counteract negative influences; thus, the risk of crime is increased (Gau et al., 2014). The breakdown of social control signals that residents do not care about 
their community and neighbourhoods. This unfortunately creates a prime location for offenders to then target victims (Boggess \& Maskaly, 2014). High crime neighbourhoods are the result of disorderly conditions and neglect by community members and lack of action from police. If society does not care about the social and physical disorder, neighbourhoods are on a slippery slope to more severe forms of disorder and crime (Engel et al., 2014). Trust and control are interlinked in the relationship between concentrated disadvantage and crime (Gau et al., 2014). Therefore, when communities fear deviant behaviour and disorder occurring in their neighbourhoods, trust and control are lost.

The concept of broken windows theory has a great impact on current policy and police enforcement (Gau \& Pratt, 2010). The ideas presented by broken windows theory and policing illustrates that police can address social and physical disorder in neighbourhoods. This implies they can prevent serious crime. "Fixing broken windows" has become the central element of crime prevention strategies and policies (Braga, Welsh \& Schnell., 2015). These range from order maintenance and zero-tolerance policing, where police attempt to impose order through strict enforcement, to community and problem oriented policing, where police attempt to produce order and reduce crime through cooperation with communities (Braga et al., 2015). Such order maintenance tasks are put in place to make the streets safer while reducing mass violence. Police and policy makers have based laws around physical and social disorders as the contributors of serious crime (Boggess \& Maskaly, 2014). Officials are able to normalize broken windows policing through discursively tailored representations of space. These broad constructions of space have a negative influence on the normalizing and problematizing of policing strategies. Urban landscapes communicate levels of neighbourhood tolerance of crime to prospective criminals (Jefferson, 2016). Community ills are expressed spatially and communal space is defined by the insider and outsider binaries. What facilitates crime is seen as exclusively local within neighbourhoods that are defined as having social and physical disorders (Jefferson, 2016). The applied belief by broken windows theory and policing is that by enforcing laws that criminalize physical and social disorders, communities can then begin to reclaim neighbourhoods.

\section{Critiques of Theory}

In the $21^{\text {st }}$ century, broken windows theory has experienced much criticism around the basis of the concept and its influence on policy and policing strategies. Broken windows theory and policing have become the subject of intense controversy, especially throughout the United States (Jefferson, 2016). This is due to police violence that is projected towards racial disparities, which results in brutality and arrests. Large rallies and protests have risen against broken windows theory and policing of such a manner (Jefferson, 2016). Within specific communities and neighbourhoods this model focuses on disorder that can be seen and interacted with. Concentrated disadvantage appears to be linked more closely with disorder than the theory allows. By focusing on disorder, this theory leaves out other influences and factors that are associated with crime that may have more substantial impacts than disorder (Gau \& Pratt, 2010). There are factors other than physical and social disorder, such as the influence of collective efficacy and community cohesion that impact crime within a community.

Collectivity and community cohesion play a strong representational role in the development and growth of neighbourhoods. When individuals become fearful of their own neighbourhoods they begin to retreat and avoid the places that cause these fears. In return, this weakens the cohesion and collective attitudes of a community (Boggess \& Maskaly, 2014). This results in a decrease in community bonds of social control and cohesion. The growth of disorder over time increases the fear of resident's, further weakening control and cohesion while increasing the vulnerability of communities to crime (Boggess \& Maskaly, 2014). Anonymity begins to increase as the level of informal social control decreases. This becomes a vicious cycle, where individuals believe if they avoid such harm or dangers they will improve the chance of protecting themselves. Instead, the opposite occurs and crimes may increase due to the lack of unity (Welsh, Braga \& Bruinsma, 2015). Therefore, there are no single factors, such as physical or social disorder, that impact crime within neighbourhoods. Instead, it is a combination of multiple factors and influences that should be considered as affecting the outcome of crime within communities.

Through analysis it is found that disorder and crime do co-occur, but it is difficult to say if the overlap is tied to "broken windows" or whether crime and disorder are sub-components of larger conditions of concentrated sociocultural disadvantage (Gau \& Pratt, 2010). Broken windows theory disregards looking at the root causes of why individuals in specific targeted areas are committing crimes or taking part in social and physical disorder. It misinterprets the relationship between disorder and crime as specifically causal and not correlated. This 
concept assumes that the ideas of crime and disorder can be separated, but this is not the case because disorder cannot cause crime if disorder is crime (Gau \& Pratt, 2010). The two constructs, crime and disorder are not distinct, but instead related identities.

Broken windows theory creates and solidifies a link between structural inequality and crime. This occurs by targeting such areas and neighbourhoods that are ridden with social and physical disorder. These disorders are seen by the general public as deviant and disturbing, but instead of helping those who need it most, they become criminalized (Jefferson, 2016). For example, within the Canadian context, broken windows theory is seen as creating the same negative effects within targeted neighbourhoods. This theory has influenced the creation of Ontario's Safe Streets Act (O'Grady, Gaetz \& Buccieri, 2013). This implemented act generates legal responses to panhandling, squeegee kids, and other forms of anti-social behaviours associated with poverty and homelessness. Bylaws have been enacted through the Safe Streets Act to curb social and physical disorders (O'Grady et al., 2013). In return, poverty and homelessness have become criminalized and policing is enforced on the basis of cities wanting these targeted people out. Tickets are being issued to individuals that cannot be paid and continue to accumulate, to the point where no help is being offered to solve the visible problems. Marginalized groups are being used as scapegoats who suffer the brunt of the punishment (O'Grady et al., 2013). This is done in attempt to please the general public and clean up what they claim and target as "problematic". Biases are implied, and individuals have a set of ideas as to who causes the problems. Unfortunately, these set of ideas and beliefs are based on labels, and stereotypes (O'Grady et al., 2013). As a result, broken windows style of enforcement and legislation is creating further issues around poverty and homelessness rather than solving the evident and ever-growing problems.

Broken windows theory is a concept that has been used to create policies and regulate police forces. Through the investigation and critique of this theory, numerous sociological theories have been discovered which further the argument that broken windows is a failing concept and misguided approach (Jefferson, 2016). The theories that can be applied are: discourse theory, labeling theory, critical race theory, and social disorganized theory. The concepts and ideas further elaborate the critiques of broken windows theory.

The discourse experienced within a society can be used to construct social realities, as explained by discourse theory (Jefferson, 2016). This can be used to analyze the social identities produced and the roles these identities play in normalizing broken windows. Identities produced through broken windows theory are those that can be expressed as conveying social or physical disorders. Identities become exclusionary when they are place based, for example, being part of a marginalized group such as the homeless (Jefferson, 2016). Social identities are shaped through a we/they binary which creates the idea of the "other". This way, individuals possess the power to further isolate marginalized people because, in their opinion, they do not fit specific constructs (Jefferson, 2016). Identities are created through beliefs and values of the dominant group. In today's society, poverty and homelessness are criminalized due to official enforcement. Therefore, anyone who falls into the category of either grouping has predetermined identities because of who they are and the situation they are in (O'Grady et al., 2013). This is what broken windows theory and policing imposes upon individuals who are then limited to resources due to the social realties that are constructed for them.

Broken windows theory labels individuals and social or physical disorders within neighbourhoods and communities. The effects of such can be explored through the use of the labeling theory. Policy makers and authorities label and classify communities as broken window areas that need to be targeted. Police then place labels and fixed identities on individuals within broken windows communities (Steenbeek \& Kreis, 2015). Individuals are labeled due to their heritage and background. The targeted areas are determined by the risk they pose to have "broken windows" and minor crimes that could escalate to more serious risk. With labeling, comes the stigmatization that is projected onto those who are seen as criminalized, due to the social and physical disorders in which they participate (Steenbeek \& Kreis, 2015). Broken windows theory and forms of policing are primarily based on labeling communities, neighbourhoods and individuals. The labels that are formed and conveyed become detrimental to the functioning of individuals within broken window communities. Labels create and pinpoint specific targets onto areas that are focused on by police and legislation (Welsh et al., 2015). Due to these constrictive labels, these areas are not helped but are rather hindered by zero-tolerance policing, which causes the continuation of this vicious cycle.

Race, stereotypes, and discrimination are factors that influence the labeling of broken windows theory in many communities. Critical race theory can be used to examine the impact of these factors. The signs and symbols of social and physical disorder may be present 
because of cultural variation or uneven development, rather than criminality (Welsh et al., 2015). The assumption is that minorities living in poor neighbourhoods are the root cause for broken windows policing because they are the individuals found in targeted areas. These individuals are faced with this reality due to stereotyping, which limits their ability to successfully participate in communities (Welsh et al., 2015). Race and dress play a role in how others perceive social and physical disorder. If an individual does not fit the specific dominant category they are targeted (Welsh et al., 2015). Racial stereotypes heighten the disorderfear relationship and crime beliefs that individuals hold within certain neighbourhoods. It is argued that measures of perceived disorder are biased by racial composition and economic disorder. The perceptions become elevated in areas where minority and poor residents are present. This is regardless of actual disorder within these given areas (Sampson \& Raudenbush, 2004). These are the types of beliefs that formulate the argument from critical race theorists around the controversial topic of broken windows. Critical race theorists' use stereotypical, discriminatory and racist beliefs as the foundation of their approach. These negative values possessed and enforced through legislation and policing are specifically what critical race theorists are drawing attention to and fighting against. Broken windows theory further solidifies and gives function to these negative aspects.

Structural factors can be seen as leading to crime and disorder which can be investigated through social disorganized theory. This theory suggests that neighbourhoods with high poverty, residential mobility, and a diverse population will have higher crime rates (Boggess \& Maskaly, 2014). The higher crime rates are a result of communities unable to realize residents' common values and maintain effective social control to reduce crime. It is expressed that certain structural factors negatively influence informal control. Crime and disorder are both manifested in the neighbourhood level of collective efficacy (Boggess \& Maskaly, 2014). Where there is low collective efficacy there are high rates of violence and disorder. Disorder should not be relied on as the only explanation to reasons of crime and "broken windows" within neighbourhoods (Boggess \& Maskaly, 2014). Social disorganized theory expresses that there are other important and influential factors that affect the outcomes within neighbours, specifically when it comes to crime (Gau et al., 2014). Each one of these theories can further explain and analyze the enforcement of broken windows and why it needs to be re-evaluated and reformed.

\section{Reforming Broken Windows}

The theory of broken windows and its influence on policy and policing needs to be reformed due to the contentious approach it has created and enforced within marginalized neighbourhoods. Reforming such a theory would involve deconstructing the ways that police portray space and crime (Boggess \& Maskaly, 2014). Stepping back from broken windows theory would create new insight and ingenuity around both ideas, and allow them to remain separate yet connected to one another. This way, space could be interpreted differently in the context of crime and disorder (Boggess \& Maskaly, 2014). Police and policy makers must stop interpreting symbols of disorder that are inscribed on human bodies and in public space as the causes of crime. Authority figures, specifically the police, need to stop targeting those who do not conform to the dominant middle-class modes of expression because this further solidifies discriminatory and stereotypical beliefs (Jefferson, 2016). Social and physical disorders should be seen as possible signs of the effect of cultural variation or uneven development rather than criminality. High crime communities should be prioritized through anti-racist policing discourse instead of broken windows (Jefferson, 2016). This means not only to look at race, but other multiple groups that are targeted and victimized by broken windows theory. Other groups to consider are: LGBTO communities, drug users, sex workers, immigrants, mentally ill, and the homeless. (Jefferson, 2016).

Another way to reform broken windows theory and its approach is to examine the link between social cohesion and control in relation to fear and dampening the disorder-fear relationship. Social cohesion is the measure of trust and integration among neighbours and is used within the social disorganization theory (Gau et al., 2014). Both social cohesion and social control can be potential mediators within communities and neighbourhoods that have high crime rates, or that were once targeted by broken windows policing. It was found that social cohesion minimized the influence of disorder and structural conditions of fear (Gau et al., 2014). Strengthening social cohesion and control would allow for communities to work together to protect themselves from crime and unwanted disorder (Gau et al., 2014). Therefore, the introduction of social cohesion and control into police enforcement would be beneficial.

The influence of broken windows theory on policing and policy would be effective if it strictly focused on problem solving by engaging in dialogue with communities. The idea of fixing broken windows is only a 
short-term solution; long term reductions require urban politicians, businesses, and community leaders working together to improve the economic fortunes of areas with high crime rates (Welsh et al., 2015). However, to completely reform broken windows theory it must be looked at from the beginning origins. This theory was created in the "old days" where there were limited technologies and much smaller communities (Dunham \& Alpert, 2015). It is argued that this theory cannot be used to explain both old and current times. Today's technology has altered the nature of police-citizen contacts (Welsh et al., 2015; Dunham \& Alpert, 2015). The use of cell phones, two-way radios, 911, and police cruisers has changed the roles of police officers and interactions between individuals on the streets (Dunham \& Alpert, 2015, pp. 468-480). Due to the shifts and changes of modern times, broken windows theory must also undergo changes to be acceptable and adaptable within today's communities. With these specific alterations broken windows policy and policing would be relevant and create beneficial outcomes within the communities that need the most support from authorities.

\section{Community Policing}

An important ideology that can be used to reevaluate broken windows theory is the idea and implementation of community policing. This idea originated through early broken windows policing and was once attempted as the main style of policing (Dunham \& Alpert, 2015). In the beginning, it did not work as expected and did not produce the anticipated results to curb crime within broken window communities. Therefore, the idea of community policing was discarded and focus was turned to the "tough on crime" mentality which was enforced through broken windows theory and policing (Dunham \& Alpert, 2015, pp.455-467). Today, society is shifting towards community policing because numerous beneficial aspects have been identified, and in response to heightened criticism towards current broken windows policing.

Community policing emerged from the desire to broaden the police mandate at a time when their effectiveness for controlling crime was questionable. Community oriented policing is found to have positive effects on citizen satisfaction, perceptions of disorder, and police legitimacy (Gill, Weisburd \& Telep, 2014). This style of policing emphasizes community involvement in crime prevention efforts and in return increases trust in police. Community policing is based on community partnerships, organizational transformation of neighbourhoods and problem solving within given areas (Gill et al., 2014). The problem-solving process draws upon citizen expertise in identifying and understanding the social issues that create crime, disorder, and fear. Community problem solving seeks to change social and physical disorder through conditions that produce significant crime reduction (Braga et al., 2015). Community members become involved through town hall meetings or learning opportunities, neighbourhood watch groups with police assistance, and police sponsored recreational activities (Braga et al., 2015). These become effective strategies that police can use in collaboration with the community to prevent crime.

Community-police relationships are built and strengthened through social cohesion and social control (Gau et al., 2014). Community policing helps reduce citizens' perceptions of social and physical disorder in their neighbourhoods and increases the feeling of safety. Citizens who feel safe and view the police as their partners are empowered to take responsibility for crime control, which creates sustainable self-regulation within communities (Gill et al., 2014). This style of policing and enforcement creates long term improvements and healthy communities that can grow and prosper together (Gill et al., 2014). If communities and individuals learn how to maintain social order, the risk of crime can be kept in check by both the citizens and police (Engel et al., 2014). From a policy perspective, it is important for police and other agencies to work with communities to define behaviour and conditions that need to be targeted. Through this collaboration, specific areas and actions can be targeted to reduce neighbourhood crime (Hinkle and Yang, 2014). The implementation of community oriented policing has promising effects on the functions within a community and is a more beneficial approach than broken windows theory policing and policy.

\section{Conclusion}

To further understand the debate around broken windows theory the research questions arise; what are the views of academics around the ideology of broken windows theory, and what are potential alternatives that could be used to change unsuccessful policy and policing? Broken windows theory is a negative outdated style of rule and policing that can be re-evaluated through numerous sociological concepts. However, the theory can be reformed to fit within the societal needs of modern day communities, so marginalized neighbourhoods are no longer oppressed by the criminalization of poverty and homelessness. This occurs through analysis and 
discussion about the overall idea of broken windows theory, the critiques towards the theory, sociological theories that explain the downfall of broken windows theory, ways the system can be reformed, and the idea of community policing. Broken windows theory is a concrete idea that has been around for many years, but now scholars are beginning to critique its influence on policy and policing (Gau et al., 2014). It is found to be not as beneficial or successful as once believed for the control of crime and disorder. Instead, it has hindered and negatively affected marginalized individuals who are criminalized through the classification and target of broken windows (Gill et al., 2014; Gau et al., 2014). Through this realization, policy and police enforcement has begun to shift towards more community oriented policing and mutual cooperation (Gill et al., 2014). By reforming broken windows theory, a new way of effective policing can be implemented and built upon to efficiently help those who have been marginalized and criminalized in the past.

\section{References}

Boggess, L., N. \& Maskaly, J. (2014). The spatial context of the disorder-crime relationship in a study of Reno neighbourhoods. Social Science Research, 43. pp. 168-183.

Braga, A., A., Welsh, B., C. \& Schnell, C. (2015). Can Policing Disorder Reduce Crime? A Systematic Review and Meta-analysis. Journal of Research in Crime and Delinquency, 53 (4). pp. 567-588.

Dunham, R., G. \& Alpert, G., P. (2015). Chapter 25: Broken Windows, by James $\mathrm{Q}$. Wilson and George L. Kelling. In Critical Issues in Policing: Contemporary Readings, Seventh Edition. pp. 455-467.

Dunham, R., G. \& Alpert, G., P. (2015). Chapter 26: "Broken Windows" and Fractured History: The Use and Misuse of History in Recent Police Patrol Analysis, by Samuel Walker. In Critical Issues in Policing: Contemporary Readings, Seventh Edition. pp. 468-480.

Engel, C., Beckenkamp, M., Glochner, A., Irlenbusch, B., Hennig-Schmidt, H., Kube, S., Kurschilgen, M., Morell, M., Nicklisch, A., Hans-Theo, N., \& Towfigh. N. (March 2014). First impressions are more important than early intervention:

Qualifying broken windows theory in the lab.
International Review of Law and Economics, 37. pp. 126-136.

Gau, J., M., Corsaro, N. \& Brunson, R., K. (2014). Revisiting broken windows theory: A test of the mediation impact of social mechanisms on the disorder-fear relationship. Journal of Criminal Justice, 42 (6). pp. 79-588.

Gau, J., M. \& Pratt, T., C. (2010). Revisiting Broken Windows Theory: Examining the Sources of the Discriminant Validity of Perceived Disorder and Crime. Journal of Criminal Justice, 38 (4). pp. 758766.

Gill, C., Weisburd, D., Telep, C., W., Vitter, Z. \& Bennett, T. (2014). Community-oriented policing to reduce crime, disorder and fear and increase satisfaction and legitimacy among citizens: a systematic review. J Exp Criminol, 10. pp. 299428.

Hinkle, J., C. \& Yang, S. (2014). A New Look into Broken Windows: What Shapes Individuals' Perceptions of Social Disorder? Journal of Criminal Justice, 42. pp. 26-35.

Jefferson, B., J. (2016). Broken Windows Policing and Constructions of Space and Crime: Flatbush, Brooklyn. Antipode: A Radical Journal of Geography, 48 (5). pp. 1270-1291.

O'Grady, B., Gaetz, S. \& Buccieri, K. (December 2013). Tickets... and More Tickets: A Case Study of the Enforcement of the Ontario Safe Streets Act. Canadian Public Policy, 39 (4). pp. 541-558.

Sampson, R., J. \& Raudenbush, S., W. (December 2004). Seeing Disorder: Neighbourhood Stigma and the Social Construction of "Broken Windows". Social Psychology Quarterly, 67 (4). pp. 319-342.

Steenbeek, W. \& Kreis, C. (2015). Where Broken Windows Should Be Fixed: Toward Identification of Areas at the Tipping Point. Journal of Research in Crime and Delinquency, 42 (4). pp. 511-533.

Welsh, B., C., Braga, A., A. \& Bruinsma, G., N. (2015). Reimaging Broken Windows: From Theory to Policy. Journal of Research in Crime and Delinquency, 52 (4). pp. 447-463 
Broken Windows Theory (Schappert)

University of Saskatchewan Undergraduate Research Journal 